\title{
Association Between Fasting Blood Glucose and All- Cause Mortality in a Rural Chinese Population: 15-Year Follow-Up Cohort Study
}

\author{
Nannan Cheng $\cdot$ Yue Zhang $\cdot$ Jie Yang $\cdot$ Jingyi Li $\cdot$ Lijing Ye $\cdot$ Ziyi Zhou \\ Zhuo Wang · Lishun Liu · Yun Song · Zhibo Yang · Guiping She · Xue Bai • \\ Xiao Huang · Xiaoshu Cheng · Genfu Tang • Binyan Wang · Xianhui Qin • \\ Pierre Zalloua $\cdot$ Fangrong Yan (D) - Xiping Xu
}

Received: August 10, 2020 / Accepted: September 10, 2020 / Published online: September 25, 2020

(c) The Author(s) 2020

\section{ABSTRACT}

Introduction: The worldwide prevalence of diabetes has been increasing for decades; diabetes can lead to serious health problems and even death, but the effects of maintaining low fasting blood glucose (FBG) remain

Digital Features To view digital features for this article go to: https://doi.org/10.6084/m9.figshare.12932966.

Electronic supplementary material The online version of this article (doi:https://doi.org/10.1007/ s13300-020-00927-6) contains supplementary material, which is available to authorized users.

N. Cheng $\cdot$ Y. Zhang $\cdot$ J. Yang $\cdot$ J. Li $\cdot$ L. Ye F. Yan $(\square)$

State Key Laboratory of Natural Medicines, Research

Center of Biostatistics and Computational

Pharmacy, China Pharmaceutical University,

Nanjing 210009, China

e-mail: f.r.yan@163.com

Z. Zhou · Z. Wang · L. Liu · Y. Song · X. Xu (ه)

Beijing Advanced Innovation Center for Food

Nutrition and Human Health, College of Food

Science and Nutritional Engineering, China

Agricultural University, Beijing, China

e-mail: xipingxu126@126.com

Z. Yang

Chinese Medicine Hospital of Zhaotong, Zhaotong,

Yunnan, China

G. She

The Second Affiliated Hospital of Shaoyang

University, Shaoyang, Hunan, China controversial. The purpose of this study was to investigate the relationship between FBG levels and all-cause mortality in a long-term follow-up cohort and to find a relatively safe range of FBG levels.

Methods: This study included 17,902 adults from a community-based cohort study in rural China who were prospectively followed from 2003 to 2018. Generalized estimating equations were used to evaluate the association between FBG and all-cause mortality, adjusting for per-

X. Bai

The Affiliated Traditional Chinese Medicine Hospital of Southwest Medical University, Luzhou, China

\section{Huang $\cdot$ X. Cheng}

Department of Cardiovascular Medicine, Second Affiliated Hospital of Nanchang University,

Nanchang, China

Y. Song · G. Tang · B. Wang

School of Health Administration, Anhui Medical University, Hefei, China

\section{B. Wang}

Shenzhen Evergreen Medical Institute, Shenzhen, China

X. Qin · X. Xu

National Clinical Research Study Center for Kidney Disease, the State Key Laboratory for Organ Failure Research; Renal Division, Nanfang Hospital, Southern Medical University, Guangzhou, China

P. Zalloua

School of Medicine, Lebanese American University, Byblos, Lebanon 
tinent covariates and auto-correlations among siblings.

Results: A total of 1053 (5.9\%) deaths occurred during 15 years of follow-up. There was a significant U-shaped association between all-cause mortality and FBG. Compared with the reference group (FBG of $5.6-<6.1 \mathrm{mmol} / \mathrm{l}$ ), the risk of death among individuals with FBG levels $<5.6 \mathrm{mmol} / \mathrm{l}$ significantly increased by 38\% (OR 1.34; 95\% CI 1.13-1.59), while the risk of death among individuals with FBG $\geq 6.1 \mathrm{mmol} / 1$ or participants with a selfreported history of diabetes significantly increased by $51 \%$ (OR 1.49; 95\% CI 1.20-1.85). Additionally, the U-shaped association remained steady in any stratification of risk factors.

Conclusion: Our study showed a significant U-shaped relationship between FBG levels and risk of all-cause mortality in this rural Chinese population. When FBG was within the range of $5.6-<6.1 \mathrm{mmol} / \mathrm{l}$, the risk of all-cause mortality was the lowest.

Keywords: All-cause mortality; Fasting blood glucose; U-shaped relationship

\section{Key Summary Points}

This is a large cohort with a population of 17,902 and a long-term (from 2003 to 2018) follow-up.

The study found a relatively safe range of fasting blood glucose (FBG) levels in this rural Chinese population.

A significant U-shaped relationship between FBG levels and risk of all-cause mortality was found in this rural Chinese population.

The American Diabetes Association (ADA) changed the definition of impaired fasting glucose (IFG) from an FBG range of 6.1-6.9 $\mathrm{mmol} / \mathrm{l}$ to $5.6-6.9 \mathrm{mmol} / \mathrm{l}$, which may not be suitable for this rural Chinese population.

\section{DIGITAL FEATURES}

This article is published with digital features to facilitate understanding of the article. To view digital features for this article go to https://doi. org/10.6084/m9.figshare.12932966

\section{INTRODUCTION}

The total number of deaths worldwide has been increasing for decades; in 1950, there were 43.7 million deaths in the world, while by 2017 , that number had increased to 55.9 million [1]. According to the National Bureau of Statistics, China's death rate in 2014 was $7.16 \%$ and in 2017 was $7.11 \%$ [2]. However, with the increase in total population and the gradual acceleration of aging of the population, the number of deaths in China continues to increase, and the burden of death will likely be greatly aggravated.

With the improvement of people's living standards, diabetes has gradually become one of the most important public health challenges in the twenty-first century. For the past few decades, the global prevalence of diabetes has increased; according to the International Diabetes Federation (IDF) 2019 report, an estimated 463 million people worldwide have diabetes, and by 2045 the number will be 700 million $[3,4]$. Many epidemiologic studies have confirmed diabetes mellitus (DM) as a recognized risk factor for all-cause mortality $[5,6]$. An article reported that the number of global deaths due to diabetes in 2000 was estimated at 2.9 million, accounting for $5.2 \%$ of all deaths [7]. Additionally, of all countries, China has the largest number of people suffering from diabetes [8].

In 1997, the American Diabetes Association (ADA) introduced the concept of impaired fasting glucose (IFG), a type of pre-diabetes defined by a patient's FBG range [9]. Many studies have found that IFG is associated with increased all-cause mortality [10-12]. In 2003, to better identify the individual risks of future DM and reduce its disease burden, the ADA changed the definition of IFG from an FBG range of $6.1-6.9 \mathrm{mmol} / \mathrm{l}$ to $5.6-6.9 \mathrm{mmol} / \mathrm{l}$ [13]. 
However, this change has caused much controversy, with some studies suggesting that the new IFG definition is related to increased allcause mortality [11, 14], while other studies showed no such association [10, 12, 15]. Determining the appropriate cut-points for fasting blood glucose and finding a relatively "safe range" of fasting blood glucose to minimize mortality will help inform the public and clinical actions to prevent deaths caused by hyperglycemia or hypoglycemia. Our study combined the two standards of IFG defined by the ADA; FBG was analyzed as a categorical variable $(<5.6,5.6-<6.1$, and $\geq 6.1 \mathrm{mmol} / \mathrm{l})$.

The purpose of our study was to investigate the relationship between fasting blood glucose levels and all-cause mortality in a Chinese rural population and to identify a relatively 'safe range' for fasting blood glucose levels. Our study is based on a rural Chinese population of low socioeconomic status. The results of the study may provide evidence for rural areas or low-nutrient populations in China.

\section{METHODS}

\section{Participants}

The study participants were all part of an original cohort of a previously conducted study on osteoporosis, who were enrolled in 2003 in Anqing, Anhui Province, in Eastern China. Anqing is located in the southwest of Anhui Province, with a current population of $6.1 \mathrm{mil}-$ lion, $90 \%$ of which are rural residents. The livelihoods of most are based on agriculture, and their economic level is relatively backward [16]. All participates were from a family of at least three siblings. Exclusion criteria included chronic infections, renal failure, history of type 1 diabetes mellitus, rickets or other metabolic bone diseases, chronic glucocorticoid use, and thyrotoxicosis. Premenopausal women who were uncertain of their pregnancy status at the time of enrollment were also excluded. All participants provided written informed consent and underwent a questionnaire survey at baseline, administered by professionally trained investigators, that included information on demographic data, lifestyle, and medical history. As part of the baseline study, blood pressure measurements and blood samples were obtained (as detailed below). The data supporting the findings of this study will be available from the corresponding author (Xiping $\mathrm{Xu}$ ) on request.

The study was approved by the ethics committee of Anhui Medical University (the committee's reference number is 1005 2003-8-11). All procedures followed ethical standards. Written informed consent was obtained from each participant. The research was performed in accordance with the Helsinki Declaration of 1964 and its later amendments and applicable local laws and regulations.

Data were obtained at baseline in 2003, and follow-up visits were conducted in 2014, in 2017, and at the study's conclusion in 2018. The study had a high percentage of follow-up as this rural population remained stable and homogeneous with respect to ethnicity, environmental factors, lifestyle, and dietary habits. The homogeneity and stability of the population are reflected in the fact that this is a population in rural Anqing. Most of them are Han farmers, and their diet, work, and rest are probably consistent. After excluding 335 participants who were missing fasting blood glucose data and family number at baseline, a total of 17,902 participants were included in this analysis (Fig. 1). During the follow-up period, a total of 1053 (5.9\%) deaths occurred.

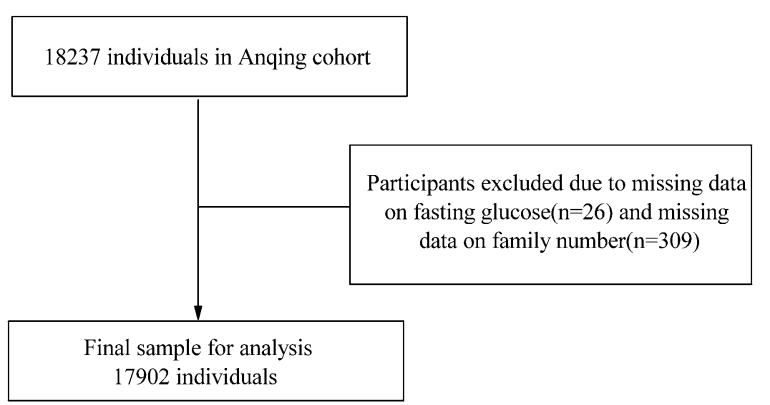

Fig. 1 Flow chart of the participants in the current study 


\section{Ascertainment of All-Cause Mortality}

The study outcome was all-cause mortality. Data on all-cause mortality were obtained by telephone or through face-to-face interviews with household members.

\section{Laboratory Assessment}

At baseline, fasting blood samples were collected and stored in aliquots at $-80^{\circ} \mathrm{C}$. Serum lipids and fasting blood glucose were measured enzymatically with a Cobas Integra Roche analyzer (Roche, Indianapolis, IN).

\section{Glucose Status Classification}

Type 2 diabetes mellitus was defined as either a fasting blood glucose concentration $\geq 7.0 \mathrm{mmol} / \mathrm{l}(126 \mathrm{mg} / \mathrm{dl})$ or a physician's previous diagnosis of diabetes (other than during pregnancy), based on the American Diabetes Association criterion. In participants who did not have a previous diagnosis of DM, the baseline fasting blood glucose concentrations were divided into the following categories: $<5.6, \geq 5.6 \quad$ and $<6.1$, and $\geq 6.1 \mathrm{mmol} / \mathrm{l} \quad(<100, \geq 100$ and $<110$, and $\geq 110 \mathrm{mg} / \mathrm{dl})$.

\section{Statistical Analyses}

Means (SD) or medians (25th percentile-75th percentile) and proportions were calculated for population characteristics by sex. Multivariable analyses were performed using generalized estimating equations (GEEs) to evaluate odds ratios (OR) and 95\% confidence intervals (CIs) of all-cause mortality risk. GEEs were used to account for autocorrelations among multiple family members. In the multivariate model, we adjusted for age, sex, body mass index (BMI), smoking status, drinking status, systolic blood pressure (SBP), diastolic blood pressure (DBP), total cholesterol (TC), triglycerides (TG), and high-density lipoprotein cholesterol (HDL-C). In the stratified analysis, lipids were divided into two groups by clinical cut-point, and interactions were tested through GEE. A twotailed $P<0.05$ was considered to be statistically significant in all analyses. Subjects were stratified by sex, age $(<50$ vs. $\geq 50$ years $)$, BMI $(<24$ vs. $\left.\geq 24 \mathrm{~kg} / \mathrm{m}^{2}\right)$, smoking and drinking status (never vs. ever), TG ( $<1.7$ vs. $\geq 1.7 \mathrm{mmol} / \mathrm{l})$, TC $(<5.2 \quad$ vs. $\geq 5.2 \mathrm{mmol} / \mathrm{l})$, HDL-C $\quad(<1.04$ vs. $\geq 1.04 \mathrm{mmol} / \mathrm{l}), \quad$ SBP $\quad(<140$ vs. $\geq 140 \mathrm{mmHg}), \quad$ and DBP $\quad(<90$ vs. $\geq 90 \mathrm{mmHg}$ ) in additional exploratory analyses. EmpowerStats (https://www. empowerstats.com) and $\mathrm{R}$ software, version 3.5.1 (https://www.R-project.org/), were used for all statistical analyses.

\section{RESULTS}

\section{Study Participants and Baseline Characteristics}

Baseline characteristics of the participants according to sex are summarized in Table 1 . Male participants were older and had higher blood pressure and HDL-C levels, while female participants tended to be younger and heavier with higher total cholesterol and triglyceride levels. Fasting blood glucose in the female population was significantly higher than in the male population. Within fasting blood glucose strata, age, blood pressure, BMI, TC, TG, and HDL levels were significantly higher as fasting blood glucose levels increased (Supplemental Table 1).

\section{Association between Fasting Blood Glucose and All-Cause Mortality}

As shown in Fig. 2, as fasting blood glucose levels increase, the smooth curves show that after adjustment for major covariates, the risk of all-cause mortality first decreases and then increases, showing a significant U-shaped relationship between fasting blood glucose levels and risk of all-cause mortality, with a nadir at around $5.6-6.1 \mathrm{mmol} / \mathrm{l}$. Consistent with the smooth curves, compared with the reference group (FBG of $5.6-<6.1 \mathrm{mmol} / \mathrm{l}$ ), the odds ratios (ORs) and 95\% confidence intervals 
Table 1 Baseline characteristics of the study participants by sex ${ }^{a}$

\begin{tabular}{|c|c|c|c|c|}
\hline \multirow[t]{2}{*}{ Variables } & \multicolumn{3}{|c|}{ Stratified by sex } & \multirow[t]{2}{*}{$P$ value } \\
\hline & Total & Males & Females & \\
\hline$N$ & 17,902 & 9054 & 8848 & \\
\hline Age (years) & $45.9(7.6)$ & $46.9(7.7)$ & $44.9(7.4)$ & $<0.001$ \\
\hline SBP, mmHg & $121.1(18.9)$ & $121.7(18.5)$ & $120.5(19.2)$ & $<0.001$ \\
\hline DBP, mmHg & $77.6(11.6)$ & $78.6(11.9)$ & $76.6(11.3)$ & $<0.001$ \\
\hline BMI, $\mathrm{kg} / \mathrm{m}^{2}$ & $21.7(2.9)$ & $21.3(2.5)$ & $22.1(3.1)$ & $<0.001$ \\
\hline \multicolumn{5}{|l|}{ Laboratory results } \\
\hline Fasting glucose, $\mathrm{mmol} / \mathrm{l}$ & $5.5(1.0)$ & $5.4(1.0)$ & $5.5(0.9)$ & 0.007 \\
\hline Total cholesterol, mmol/l & $4.4(0.8)$ & $4.4(0.8)$ & $4.4(0.9)$ & $<0.001$ \\
\hline Triglycerides, mmol/l & $1.3(0.9)$ & $1.2(1.0)$ & $1.4(0.9)$ & $<0.001$ \\
\hline HDL cholesterol, mmol/l & $1.4(0.4)$ & $1.4(0.4)$ & $1.4(0.3)$ & $<0.001$ \\
\hline Smoking status, $n(\%)$ & & & & $<0.001$ \\
\hline Never & $10,440(58.6)$ & $1919(21.3)$ & $8521(96.6)$ & \\
\hline Former & $786(4.4)$ & $763(8.5)$ & $23(0.3)$ & \\
\hline Current & $6603(37.0)$ & $6328(70.2)$ & $275(3.1)$ & \\
\hline Drinking status, $n(\%)$ & & & & $<0.001$ \\
\hline Never & $13,574(76.2)$ & $4982(55.3)$ & $8592(97.5)$ & \\
\hline Former & $252(1.4)$ & $226(2.5)$ & $26(0.3)$ & \\
\hline Current & 3999 (22.4) & $3803(42.2)$ & $196(2.2)$ & \\
\hline
\end{tabular}

$B M I$ body mass index, SBP systolic blood pressure, DBP diastolic blood pressure, $H D L$ high-density lipoprotein

${ }^{a}$ For continuous variables, values are presented as mean (SD). For categorical variables, values are presented as $n$ (\%)

(CIs) for all-cause mortality for group 1 of the fasting blood glucose categories of $<4.75,4.75$ $-<5.6,6.1-<7.0$, and $\geq 7.0 \mathrm{mmol} / \mathrm{l}$ or $\mathrm{DM}$ were 1.31 (1.02-1.69), 1.35 (1.14-1.60), 1.34 (1.06-1.70), and 2.00 (1.45-2.76), respectively. A similar pattern was observed for group 2 when we combined the categories of fasting blood glucose into $<5.6$ and $\geq 6.1$. Compared with the reference group (FBG of $5.6-<6.1 \mathrm{mmol} / \mathrm{l}$ ), the risk of death among individuals with fasting blood glucose levels $<5.6 \mathrm{mmol} / \mathrm{l}$ significantly increased by $34 \%$ (OR 1.34; 95\% CI 1.13-1.59), while the risk of death among individuals with fasting blood glucose $\geq 6.1 \mathrm{mmol} / \mathrm{l}$ or participants who had a self-reported history of diabetes significantly increased by $49 \%$ (OR 1.49; 95\% CI 1.20-1.85) (Table 2). Additionally, there was a similar pattern when fasting blood glucose was divided into six equal groups (Supplemental Table 2).

\section{Stratified Analyses on Fasting Blood Glucose and All-Cause Mortality}

We further performed stratified analyses to assess the effects of FBG on all-cause mortality in various subgroups (Table 3). None of the following variables, including age, sex, BMI, SBP, DBP, smoking status, drinking status, triglycerides, total cholesterol, and high-density 


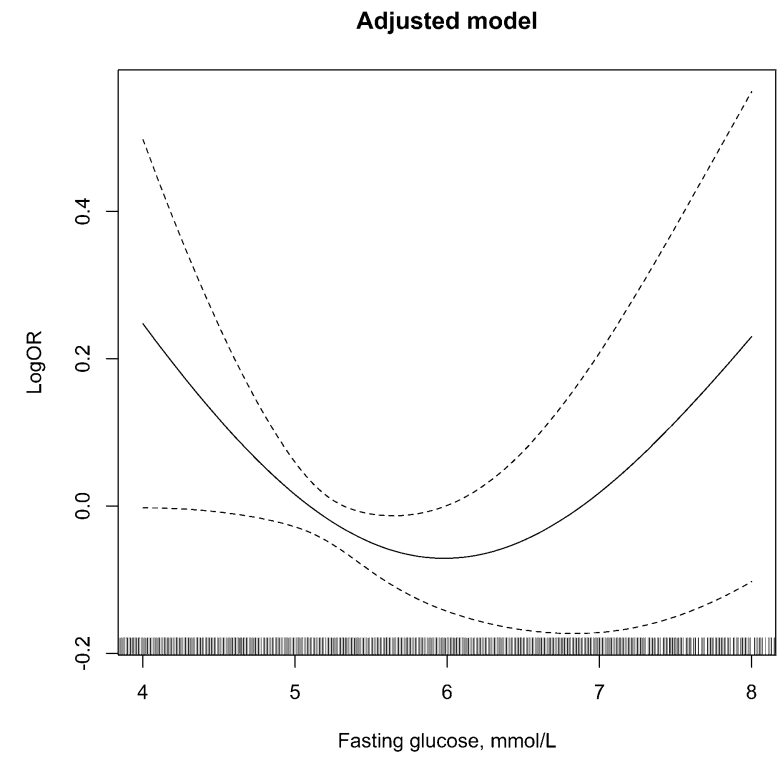

Fig. 2 Association between baseline fasting glucose and risk of all-cause mortality. Model adjusted for age, sex, systolic blood pressure, diastolic blood pressure, body mass index, total cholesterol, triglycerides, HDL cholesterol, and smoking and drinking status lipoprotein cholesterol, significantly modified the association between fasting blood glucose and all-cause mortality. Compared with the reference group (FBG of $5.6-<6.1 \mathrm{mmol} / \mathrm{l}$ ), the risk of all-cause mortality in the fasting blood glucose categories of $<5.6 \mathrm{mmol} / \mathrm{l}$ or $\geq 6.1 \mathrm{mmol} / 1$ increased across all stratifications by risk factors, showing a stable U-shaped relationship between fasting blood glucose levels and all-cause mortality.

\section{DISCUSSION}

In our study, FBG was analyzed categorically $(<5.6,5.6-<6.1, \geq 6.1 \mathrm{mmol} / \mathrm{l})$. This study showed a significant U-shaped relationship between fasting blood glucose levels and risk of all-cause mortality in the study population. After adjustment for possible confounding factors, it was found that the risk of all-cause mortality was lowest when fasting blood glucose was in the level of $5.6-<6.1 \mathrm{mmol} / \mathrm{l}$, suggesting that a 'safe range' for fasting blood glucose concentrations exists between 5.6

Table 2 Association between fasting glucose and all-cause mortality

\begin{tabular}{|c|c|c|c|c|c|}
\hline Fasting glucose, $\mathrm{mmol} / \mathrm{l}$ & $N$ & Case (\%) & $\begin{array}{l}\text { Crude model } \\
\text { OR }(95 \% \mathrm{CI})\end{array}$ & $\begin{array}{l}\text { Adjusted model } \\
\text { OR }(95 \% \mathrm{CI})\end{array}$ & $P$ value \\
\hline \multicolumn{6}{|l|}{ Group $1^{\mathrm{b}}$} \\
\hline$<4.75$ & 1987 & $110(5.5)$ & $1.11(0.87-1.42)$ & $1.31(1.02-1.69)$ & 0.035 \\
\hline $4.75-<5.6$ & 10,093 & $590(5.9)$ & $1.17(0.99-1.40)$ & $1.35(1.14-1.60)$ & $<0.001$ \\
\hline $5.6-<6.1$ & 3545 & $178(5.0)$ & Ref. & Ref. & \\
\hline $6.1-<7.0$ & 1765 & $120(6.8)$ & $1.38(1.09-1.75)$ & $1.34(1.06-1.70)$ & 0.016 \\
\hline$\geq 7.0$ or $\mathrm{DM}$ & 512 & $55(10.7)$ & $2.28(1.66-3.13)$ & $2.00(1.45-2.76)$ & $<0.001$ \\
\hline \multicolumn{6}{|l|}{ Group $2^{\mathrm{b}}$} \\
\hline$<5.6$ & 12,080 & $700(5.8)$ & $1.16(0.98-1.38)$ & $1.34(1.13-1.59)$ & $<0.001$ \\
\hline $5.6-<6.1$ & 3545 & $178(5.0)$ & Ref. & Ref. & \\
\hline$\geq 6.1$ or $\mathrm{DM}$ & 2277 & $175(7.7)$ & $1.57(1.27-1.95)$ & $1.49(1.20-1.85)$ & $<0.001$ \\
\hline
\end{tabular}

a Adjusted for age, sex, systolic blood pressure, diastolic blood pressure, body mass index, total cholesterol, triglycerides, HDL cholesterol, and smoking and drinking status

b Group 1: the fasting blood glucose categories of $<4.75,4.75-<5.6,5.6-<6.1,6.1-<7.0$, and $\geq 7.0 \mathrm{mmol} / 1 \mathrm{or}$ DM; group 2: the fasting blood glucose categories of $<5.6,5.6-<6.1$, and $\geq 6.1 \mathrm{mmol} / \mathrm{l}$ or DM 
Table 3 Association among all-cause mortality and fasting glucose, stratified by risk factors

\begin{tabular}{|c|c|c|c|c|c|c|c|}
\hline & \multicolumn{2}{|c|}{ FPG $<5.6 \mathrm{mmol} / 1$} & \multicolumn{2}{|c|}{ FPG $5.6-6.1 \mathrm{mmol} / 1$} & \multicolumn{2}{|c|}{ FPG $\geq 6.1 \mathrm{mmol} / 1$ or $\mathrm{DM}$} & \multirow[t]{2}{*}{$P$ for interaction } \\
\hline & Events (\%) & OR $(95 \% C I)$ & $\overline{\text { Events (\%) }}$ & $\overline{\text { OR }(95 \% C I)}$ & $\overline{\text { Events (\%) }}$ & OR $(95 \% \mathrm{CI})$ & \\
\hline Sex & & & & & & & 0.88 \\
\hline Female & $209(3.6)$ & $1.42(1.05-1.92)$ & $54(3.0)$ & Ref. & $60(5.0)$ & $1.45(1.00-2.11)$ & \\
\hline Male & $491(7.9)$ & $1.31(1.06-1.61)$ & $124(7.1)$ & Ref. & $115(10.7)$ & $1.52(1.16-1.99)$ & \\
\hline Age (years) & & & & & & & 0.19 \\
\hline$<50$ & $329(3.8)$ & $1.61(1.21-2.15)$ & $56(2.5)$ & Ref. & $58(4.3)$ & $1.72(1.18-2.49)$ & \\
\hline$\geq 50$ & $371(10.9)$ & $1.15(0.93-1.43)$ & $122(9.3)$ & Ref. & $117(12.6)$ & $1.38(1.05-1.81)$ & \\
\hline Smoking status & & & & & & & 0.74 \\
\hline Never & $258(3.7)$ & $1.29(1.00-1.67)$ & $77(3.6)$ & Ref. & $77(5.5)$ & $1.38(0.99-1.91)$ & \\
\hline Former & $58(11.5)$ & $1.45(0.80-2.63)$ & $18(10.0)$ & Ref. & $11(10.8)$ & $1.09(0.49-2.42)$ & \\
\hline Current & $381(8.2)$ & $1.39(1.09-1.77)$ & $82(6.8)$ & Ref. & $85(11.3)$ & $1.68(1.23-2.30)$ & \\
\hline Drinking status & & & & & & & 0.85 \\
\hline Never & $465(5.1)$ & $1.41(1.14-1.74)$ & $113(4.2)$ & Ref. & $117(6.8)$ & $1.50(1.15-1.96)$ & \\
\hline Former & $33(20.9)$ & $1.50(0.71-3.15)$ & $11(17.5)$ & Ref. & $7(22.6)$ & $1.39(0.47-4.10)$ & \\
\hline Current & $198(7.3)$ & $1.17(0.85-1.60)$ & $53(6.8)$ & Ref. & $50(9.9)$ & $1.46(0.97-2.18)$ & \\
\hline Systolic blood $\mathrm{p}$ & ressure, $\mathrm{mmHg}$ & & & & & & 0.33 \\
\hline$<140$ & $551(5.2)$ & $1.33(1.10-1.62)$ & $128(4.4)$ & Ref. & $104(6.1)$ & $1.34(1.03-1.75)$ & \\
\hline$\geq 140$ & $148(9.6)$ & $1.26(0.89-1.78)$ & $49(8.1)$ & Ref. & $70(12.6)$ & $1.73(1.16-2.59)$ & \\
\hline Diastolic blood & pressure, $\mathrm{mmHg}$ & & & & & & 0.62 \\
\hline$<90$ & $562(5.3)$ & $1.30(1.08-1.58)$ & $136(4.6)$ & Ref. & $123(6.7)$ & $1.42(1.10-1.83)$ & \\
\hline$\geq 90$ & $137(9.0)$ & $1.39(0.96-2.02)$ & $42(7.1)$ & Ref. & $51(12.0)$ & $1.79(1.14-2.81)$ & \\
\hline Total cholestero & $\mathrm{l}, \mathrm{mmol} / \mathrm{l}$ & & & & & & 0.99 \\
\hline$<5.2$ & $593(5.7)$ & $1.33(1.10-1.61)$ & $144(4.9)$ & Ref. & $139(7.6)$ & $1.51(1.19-1.93)$ & \\
\hline$\geq 5.2$ & $107(6.1)$ & $1.35(0.89-2.07)$ & $34(5.5)$ & Ref. & $36(7.9)$ & $1.40(0.84-2.33)$ & \\
\hline Triglycerides, $\mathrm{m}$ & $\mathrm{mol} / \mathrm{l}$ & & & & & & 0.56 \\
\hline$<1.7$ & $599(5.9)$ & $1.41(1.17-1.70)$ & $141(4.8)$ & Ref. & $134(7.8)$ & $1.52(1.19-1.94)$ & \\
\hline$\geq 1.7$ & $101(5.3)$ & $1.12(0.75-1.67)$ & $37(5.9)$ & Ref. & $41(7.5)$ & $1.36(0.85-2.18)$ & \\
\hline High density lip & oprotein, $\mathrm{mmol} / \mathrm{l}$ & & & & & & 0.32 \\
\hline$<1.04$ & $125(6.1)$ & $1.88(1.11-3.18)$ & $17(3.8)$ & Ref. & $24(7.8)$ & $1.81(0.93-3.51)$ & \\
\hline$\geq 1.04$ & $575(5.7)$ & $1.26(1.05-1.52)$ & $161(5.2)$ & Ref. & $151(7.7)$ & $1.45(1.15-1.83)$ & \\
\hline Body mass index & $\mathrm{x}, \mathrm{kg} / \mathrm{m}^{2}$ & & & & & & 0.83 \\
\hline$<24$ & $609(6.1)$ & $1.33(1.10-1.59)$ & $152(5.4)$ & Ref. & $144(8.2)$ & $1.48(1.17-1.88)$ & \\
\hline$\geq 24$ & $90(4.3)$ & $1.41(0.91-2.33)$ & $25(3.5)$ & Ref. & $29(5.7)$ & $1.57(0.90-2.75)$ & \\
\hline
\end{tabular}

Adjusted, if not stratified, for age, sex, systolic blood pressure, diastolic blood pressure, body mass index, total cholesterol, triglycerides, HDL cholesterol, and smoking and drinking status

and $<6.1 \mathrm{mmol} / \mathrm{l}$. Compared with the reference group (FBG of $5.6-<6.1 \mathrm{mmol} / \mathrm{l}$ ), the risk of death significantly increased in the groups with fasting blood glucose $<5.6 \mathrm{mmol} / \mathrm{l}$ or equal to or above $6.1 \mathrm{mmol} / \mathrm{l}$.

The worldwide prevalence of diabetes has been increasing for decades; diabetes can lead to serious health problems and even death [3-8]. Both hypoglycemia and hyperglycemia are significantly associated with adverse outcomes [17]. However, controversy regarding the association between fasting blood glucose and allcause mortality still exists. A prospective study of a Korean population found a J-shaped association between fasting blood glucose levels and all-cause mortality, with a nadir at around 80-94 mg/dl (4.4-5.2 mmol/l) in both men and women; both low and high fasting blood 
glucose concentrations were associated with a higher risk of mortality [18]. Wändell et al. also found a similar J-shaped curve relationship between fasting glucose levels and all-cause mortality [19]. However, a study including a stratified sample of participants $(n=17,287)$ from the Women's Health Initiative (WHI) showed that a fasting blood glucose level > $100 \mathrm{mg} / \mathrm{ml}$ increased the risk for cardiovascular disease and all-cause mortality. The study found no significant association with low fasting glucose (HR 0.97; 95\% CI 0.79-1.20) [20].

Yanhong $\mathrm{Li}$ et al. found a U-shaped relationship between early blood glucose concentrations and PICU mortality. When the blood glucose concentration is $110-140 \mathrm{mg} / \mathrm{dl}$ (6.1-$7.8 \mathrm{mmol} / \mathrm{l})$, the risk of all-cause mortality is the lowest [17]. The People's Republic of China-USA (PRC-USA) collaborative study also found a significant U-shaped relationship between fasting blood glucose levels and all-cause mortality, and the result of the study showed that both low $(<80 \mathrm{mg} / \mathrm{dl})$ and high $(\geq 126 \mathrm{mg} / \mathrm{dl})$ fasting blood glucose levels were significantly associated with increased risk of all-cause and cardiovascular disease mortality in the Chinese general population[21].

Our results showed that fasting blood glucose levels in this population had a significant U-shaped relationship with mortality risk and that this relationship was not affected by other risk factors; both higher and lower fasting blood glucose levels were significantly associated with increased risk of all-cause mortality, which is consistent with the results of some studies $[17-19,21]$. The mechanism for the association between high fasting blood glucose levels and risk of all-cause mortality is very clear; high fasting blood glucose causes complications such as CVD and chronic kidney disease, both of which increase the risk of death [21]. While the mechanism for the relationship between low fasting blood glucose and risk of all-cause mortality is not that clear, studies have shown that hypoglycemia may be associated with low energy consumption, resulting in poor health and increased bodily susceptibility to diseases, thus increasing the risk of death [22]. Additionally, other studies have suggested that the relationship between low levels of fasting blood glucose and all-cause mortality risk may be explained by brain damage during hypoglycemia [23]. Our study is based on a rural Chinese population, of low socioeconomic status. It may be that inadequate intake of nutrients in this population leads to an increased risk of death from malnutrition. This study provides a relatively safe fasting blood glucose range (5.6 $-<6.1 \mathrm{mmol} / \mathrm{l}$ ) for the regional population in rural China, but this relatively safe fasting blood glucose range is higher than in previous studies, probably because our population generally has a low BMI, which may be caused by malnutrition. Therefore, more trials are needed to verify the results.

However, there are still several limitations to this study. First, we did not have information on specific causes of mortality. In addition, recall bias could exist. Because we conducted household or telephone interviews at follow-up visits, we failed to collect the time of death in time, resulting in the inability to use the Cox model to better predict the correlation between blood glucose and all-cause mortality. Second, we did not obtain information on patient medication usage for diabetes and/or a time variable to better predict the association between fasting blood glucose and all-cause mortality. Third, during the follow-up, we did not have complete fasting blood glucose measurements for each participant. Therefore, we could not assess the association between mean fasting blood glucose and all-cause mortality risk during follow-up. Finally, although this cohort study was designed to explore the association between fasting blood glucose and allcause mortality, all study participants were from rural areas in Anhui Province; therefore, the findings of this study cannot be extended to a wider population.

\section{CONCLUSION}

This study showed a significant U-shaped relationship between fasting blood glucose levels and risk of all-cause mortality in a rural Chinese population. Both low and high fasting blood glucose concentrations were associated with higher mortality in this study population. 
When fasting blood glucose was at the level of $5.6-<6.1 \mathrm{mmol} / \mathrm{l}$, the risk of mortality was lowest, and when blood glucose was < $5.6 \mathrm{mmol} / \mathrm{l}$ or $\geq 6.1 \mathrm{mmol} / \mathrm{l}$, the risk of death increased significantly. Controlled fasting blood glucose levels within the $5.6-<6.1 \mathrm{mmol} / \mathrm{l}$ range appear to be relatively safe.

\section{ACKNOWLEDGEMENTS}

We thank the investigators and participants in the osteoporosis cohort study, the parent study, who made this report possible.

Funding. The study was supported by funding from the following: the National Key Research and Development Program (2016YFE0205400, 2018ZX09739010, 2018ZX09301034003), the Science and Technology Planning Project of Guangzhou, China (201707020010), the Science, Technology, and Innovation Committee of Shenzhen (GJHS20170314114526143,

JSGG20180703155802047), the Economic, Trade and Information Commission of Shenzhen Municipality (20170505161556110, 20170505160926390, 201705051617070), the National Natural Science Foundation of China (81730019, 81973133, 81960074, 81500233), Jiangxi Outstanding Person Foundation (20192BCBL23024), and the Major Projects of the Science and Technology Department, Jiangxi (20171BAB205008). The journal's Rapid Service Fee was paid by the authors. Xiping Xu, the PI of the osteoporosis cohort study, has full access to all of the data in the study and takes responsibility for the integrity of the data and the accuracy of the data analysis.

Authorship. All named authors meet the International Committee of Medical Journal Editors (ICMJE) criteria for authorship for this article, take responsibility for the integrity of the work as a whole, and have given their approval for this version to be published.

Disclosures. Xiping Xu reports grants from the National Key Research and Development
Program (2016YFE0205400, 2018ZX09739010, 2018ZX09301034003), the Science and Technology Planning Project of Guangzhou, China (201707020010), the Science, Technology and Innovation Committee of Shenzhen (GJHS20170314114526143,

JSGG20180703155802047), and the Economic, Trade and Information Commission of Shenzhen Municipality (20170505161556110, 20170505160926390, 201705051617070). Xianhui Qin reports grants from the National Natural Science Foundation of China (81730019, 81973133). Xiao Huang reports grants from the National Natural Science Foundation of China (81960074, 81500233), the Jiangxi Outstanding Person Foundation (20192BCBL23024), and Major Projects of the Science and Technology Department, Jiangxi (20171BAB205008). Nannan Cheng, Yue Zhang, Jie Yang, Jingyi Li, Lijing Ye, Ziyi Zhou, Zhuo Wang, Lishun Liu, Yun Song, Zhibo Yang, Guiping She, Xue Bai, Xiaoshu Cheng, Genfu Tang, Binyan Wang, Pierre Zalloua, and Fangrong Yan have nothing to disclose.

Compliance with Ethics Guidelines. The study was approved by the ethics committee of Anhui Medical University (The committee's reference number is 1005 2003-8-11). All procedures followed ethical standards. Written informed consent was obtained from each participant. The research was performed in accordance with the Helsinki Declaration of 1964 and its later amendments and applicable local laws and regulations.

Data Availability. Data described in the manuscript, code book, and analytic code will be made available from the corresponding authors on request, after the request has been submitted and formally reviewed and approved by the Ethics Committee of the Institute of Biomedicine, Anhui Medical University, Hefei, China.

Open Access. This article is licensed under a Creative Commons Attribution-NonCommercial 4.0 International License, which permits any non-commercial use, sharing, adaptation, distribution and reproduction in any medium 
or format, as long as you give appropriate credit to the original author(s) and the source, provide a link to the Creative Commons licence, and indicate if changes were made. The images or other third party material in this article are included in the article's Creative Commons licence, unless indicated otherwise in a credit line to the material. If material is not included in the article's Creative Commons licence and your intended use is not permitted by statutory regulation or exceeds the permitted use, you will need to obtain permission directly from the copyright holder. To view a copy of this licence, visit http://creativecommons.org/licenses/by$\mathrm{nc} / 4.0 /$.

\section{REFERENCES}

1. Dicker D, Nguyen G, Abate D, et al. Global, regional, and national age-sex-specific mortality and life expectancy, 1950-2017: a systematic analysis for the Global Burden of Disease Study 2017. Lancet. 2018;392:1684-735.

2. National Bureau of Statistics of China. National data. https://www.stats.gov.cn/tjsj/ndsj/2018/ indexch.htm (Accessed April 8, 2018).

3. Zimmet P, Alberti KG, Magliano DJ, Bennett PH. Diabetes mellitus statistics on prevalence and mortality: facts and fallacies. Nat Rev Endocrinol. 2016;12:616-22.

4. Saeedi P, Petersohn I, Salpea P, et al. Global and regional diabetes prevalence estimates for 2019 and projections for 2030 and 2045: results from the International Diabetes Federation Diabetes Atlas, 9th edition. Diabetes Care. 2019;157:107843.

5. Roglic G, Unwin N. Mortality attributable to diabetes: estimates for the year 2010. Diabetes Res Clin Pract. 2010;87:15-9.

6. Mathers CD, Loncar D. Projections of global mortality and burden of disease from 2002 to 2030 . PLoS Med. 2006;3:e442.

7. Roglic G, Unwin N, Bennett PH, et al. The burden of mortality attributable to diabetes: realistic estimates for the year 2000. Diabetes Care. 2005;28:2130-5.

8. Khursheed R, Singh SK, Wadhwa S, et al. Treatment strategies against diabetes: Success so far and challenges ahead. Eur J Pharmacol. 2019;862:172625.
9. Rodriguez BL, Abbott RD, Fujimoto W, et al. The American Diabetes Association and World Health Organization Classifications for Diabetes Their impact on diabetes prevalence and total and cardiovascular disease mortality in elderly Japanese-American men. Diabetes Care. 2002;25: 951-5.

10. Huang Y, Cai X, Chen P, et al. Associations of prediabetes with all-cause and cardiovascular mortality: a meta-analysis. Ann Med. 2014;46:684-92.

11. Huang Y, Cai X, Mai W, Li M, Hu Y. Association between prediabetes and risk of cardiovascular disease and all cause mortality: systematic review and meta-analysis. BMJ. 2016;355:i5953.

12. Wen CP, Cheng TY, Tsai SP, Hsu HL, Wang SL. Increased mortality risks of pre-diabetes (impaired fasting glucose) in Taiwan. Diabetes Care. 2005;28: 2756-61.

13. Genuth S, Alberti KG, Bennett P, et al. Follow-up report on the diagnosis of diabetes mellitus. Diabetes Care. 2003;26:3160-7.

14. Laukkanen JA, Mäkikallio TH, Ronkainen K, et al. Impaired fasting plasma glucose and type 2 diabetes are related to the risk of out of hospital sudden cardiac death and all cause mortality. Diabetes Care. 2013;36:1166-71.

15. De Abreu LLF, Holloway KL, Mohebbi M, et al. Allcause mortality risk in australian women with impaired fasting glucose and diabetes. J Diabetes Res. 2017;2017:2042980.

16. Feng $\mathrm{Y}, \mathrm{Hsu} \mathrm{YH}$, Terwedow $\mathrm{H}$, et al. Familial aggregation of bone mineral density and bone mineral content in a Chinese population. Osteoporos Int. 2005;16:1917-23.

17. Li Y, Bai Z, Li M, et al. U-shaped relationship between early blood glucose and mortality in critically ill children. BMC Pediatr. 2015;15:88.

18. Yi SW, Park S, Lee YH, et al. Association between fasting glucose and all-cause mortality according to sex and age: a prospective cohort study. Sci Rep. 2017;7(1):8194.

19. Wändell PE, Theobald $\mathrm{H}$. The association between blood glucose value and long-term mortality. Diabetes Metab. 2005;31:588-94.

20. Mongraw-Chaffin M, LaCroix AZ, Sears DD, et al. A prospective study of low fasting glucose with cardiovascular disease events and all-cause mortality: the women's health initiative. Metabolism. 2017;70:116-24. 
21. Zhang Y, Niu J, Choi HK. Excess mortality among persons with type 2 diabetes. $\mathrm{N}$ Engl J Med. 2016;374:788.

22. Zhou L, Mai JZ, Li Y, et al. Fasting glucose and its association with 20-year all-cause and cause-specific mortality in Chinese general population. Chronic Dis Transl Med. 2018;5:89-96.

23. Wei M, Gibbons LW, Mitchell TL, et al. Low fasting plasma glucose level as a predictor of cardiovascular disease and all-cause mortality. Circulation. 2000;101:2047-52. 